\title{
The draft genome of whitefly Bemisia tabaci MEAM1, a global crop pest, provides novel insights into virus transmission, host adaptation, and insecticide resistance
}

Wenbo Chen ${ }^{1 \dagger}$, Daniel K. Hasegawa ${ }^{1,2+}$, Navneet Kaur ${ }^{3}$, Adi Kliot ${ }^{4}$, Patricia Valle Pinheiro ${ }^{1,5,6}$, Junbo Luan ${ }^{6}$, Marcus C. Stensmyr ${ }^{7}$, Yi Zheng ${ }^{1}$, Wenli Liu' ${ }^{1}$, Honghe Sun ${ }^{1}$, Yimin Xu ${ }^{1}$, Yuan Luo ${ }^{6}$, Angela Kruse ${ }^{1,8}$, Xiaowei Yang ${ }^{6}$, Svetlana Kontsedalov ${ }^{4}$, Galina Lebedev ${ }^{4}$, Tonja W. Fisher ${ }^{9}$, David R. Nelson ${ }^{10}$, Wayne B. Hunter ${ }^{11}$, Judith K. Brown ${ }^{8}$, Georg Jander ${ }^{1}$, Michelle Cilia ${ }^{1,7,12}$, Angela E. Douglas ${ }^{6}$, Murad Ghanim ${ }^{4}$, Alvin M. Simmons ${ }^{2}$,

William M. Wintermante ${ }^{3^{*}}$, Kai-Shu Ling ${ }^{2^{*}}$ and Zhangjun Fei ${ }^{1,12^{*}}$ (iD

\begin{abstract}
Background: The whitefly Bemisia tabaci (Hemiptera: Aleyrodidae) is among the 100 worst invasive species in the world. As one of the most important crop pests and virus vectors, B. tabaci causes substantial crop losses and poses a serious threat to global food security.

Results: We report the 615-Mb high-quality genome sequence of B. tabaci Middle East-Asia Minor 1 (MEAM1), the first genome sequence in the Aleyrodidae family, which contains 15,664 protein-coding genes. The B. tabaci genome is highly divergent from other sequenced hemipteran genomes, sharing no detectable synteny. A number of known detoxification gene families, including cytochrome P450s and UDP-glucuronosyltransferases, are significantly expanded in B. tabaci. Other expanded gene families, including cathepsins, large clusters of tandemly duplicated B. tabaci-specific genes, and phosphatidylethanolamine-binding proteins (PEBPs), were found to be associated with virus acquisition and transmission and/or insecticide resistance, likely contributing to the global invasiveness and efficient virus transmission capacity of B. tabaci. The presence of 142 horizontally transferred genes from bacteria or fungi in the $B$. tabaci genome, including genes encoding hopanoid/sterol synthesis and xenobiotic detoxification enzymes that are not present in other insects, offers novel insights into the unique biological adaptations of this insect such as polyphagy and insecticide resistance. Interestingly, two adjacent bacterial pantothenate biosynthesis genes, panB and panC, have been co-transferred into B. tabaci and fused into a single gene that has acquired introns during its evolution.

\footnotetext{
* Correspondence: bill.wintermantel@ars.usda.gov; kai.ling@ars.usda.gov; zf25@cornell.edu

'Equal contributors

${ }^{3}$ US Department of Agriculture-Agricultural Research Service, Crop Improvement and Protection Research, Salinas, CA 93905, USA

${ }^{2}$ US Department of Agriculture-Agricultural Research Service, US Vegetable Laboratory, Charleston, SC 29414, USA

'Boyce Thompson Institute, Cornell University, Ithaca, NY 14853, USA

Full list of author information is available at the end of the article
} 
(Continued from previous page)

Conclusions: The B. tabaci genome contains numerous genetic novelties, including expansions in gene families associated with insecticide resistance, detoxification and virus transmission, as well as numerous horizontally transferred genes from bacteria and fungi. We believe these novelties likely have shaped B. tabaci as a highly invasive polyphagous crop pest and efficient vector of plant viruses. The genome serves as a reference for resolving the $B$. tabaci cryptic species complex, understanding fundamental biological novelties, and providing valuable genetic information to assist the development of novel strategies for controlling whiteflies and the viruses they transmit.

Keywords: Whitefly, Bemisia tabaci, Draft genome, Virus transmission, Polyphagy, Insecticide resistance

\section{Background}

Whiteflies are notorious agricultural pests that have become major threats to global food security and cause damage to crops by direct feeding and efficient transmission of numerous viruses infecting food, fiber, and ornamental crops worldwide. Among the 1556 known whitefly species in 161 genera [1], Bemisia tabaci (Hemiptera: Aleyrodidae) is particularly important because of its ability to infest more than 1000 plant species [2] and transmit more than 300 plant pathogenic viruses [3]. Major crops affected by B. tabaci-transmitted viruses on a global scale include tomato, cassava, cotton, cucurbits, sweet potato, and numerous other species. Bemisia tabaci-transmitted Tomato yellow leaf curl virus (TYLCV) causes one of the most devastating diseases affecting tomato production [4] and has spread globally [5], while outbreaks of cassava mosaic disease (CMD) and cassava brown streak disease (CBSD) have reached epidemic levels in Africa [6-8] and are so severe that the global alliance on cassava virus research has declared war against whiteflies and the viruses they transmit [9]. Furthermore, increasing global commodity trade, climate change, and intensive crop production are facilitating both the global dispersal and the development of superabundant populations of $B$. tabaci, one of the 100 worst invasive alien species in the world (http://www.issg.org).

Bemisia tabaci was first identified as a new pest species in 1889 in Greece [10] and is now recognized to comprise multiple genetic groups, also known as "biotypes" [11]. Early work that assigned B. tabaci to various biotypes on the basis of several biological properties such as host range, behavior, insecticide resistance, and virus transmission capacity $[12,13]$ has been replaced by more reliable molecular criteria for $B$. tabaci differentiation. For example, at least 34 genetic groups (or cryptic species) of B. tabaci have been discriminated based on the sequence divergence of the mitochondrial cytochrome oxidase I (MtCOI) gene [14-17], including two globally important pest taxa: Middle East-Asia Minor 1 (MEAM1, formerly biotype $\mathrm{B}$ ) and Mediterranean (MED, formerly biotype Q) $[16,18]$.
Despite its agronomic importance, genomic resources for the B. tabaci whitefly are limited. Multiple transcriptome data are available, addressing the phylogenetic relationship and transcriptome sequence divergence of different $B$. tabaci species $[19,20]$, responses to a begomovirus [21], insecticide resistance [22], development and organ-specific patterns of gene expression [23-25], and the interactions with symbiotic bacteria required by the insect [26]. However, a fully sequenced B. tabaci genome is still greatly needed for further resolution of the species complex conundrum. In addition, a reference genome will assist our understanding of the molecular mechanisms underlying virus transmission, detoxification, host adaptation, and insecticide resistance.

Here, we present a high-quality draft genome sequence of B. tabaci MEAM1, which was assembled using a hybrid approach involving Illumina short reads and PacBio long reads. This assembly represents the first genome sequence of a member of the family Aleyrodidae. The availability of the B. tabaci genome not only provides novel insights into the underlying mechanisms of the whitefly's global invasiveness and high virus transmission capacity but also presents valuable information to help understand the B. tabaci species complex and to facilitate the development of improved strategies for efficient whitefly management.

\section{Results and discussion}

\section{The genome of $B$. tabaci}

Whiteflies from a B. tabaci colony established from a single female collected at the United States Department of Agriculture (USDA)-Agricultural Research Service (ARS) in Charleston, South Carolina (SC) were used for genome sequencing (Fig. 1a and Additional file 1: Figure S1). Polymerase chain reaction (PCR) analysis using primers against the mitochondrial cytochrome oxidase I (MtCOI) gene [27] indicates that the colony is a member of the MEAM1 species. A total of $203.8 \mathrm{~Gb}$ high-quality cleaned Illumina sequences and $4 \mathrm{~Gb}$ PacBio long reads were generated (Additional file 2), which represented $\sim 300$-fold coverage of the B. tabaci MEAM1 genome, which has an 


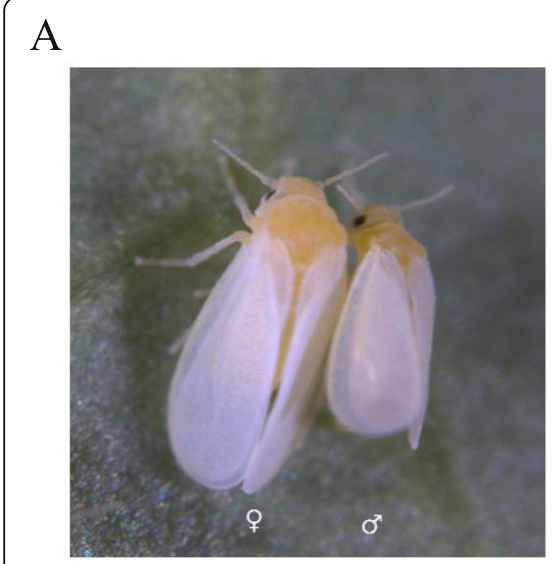

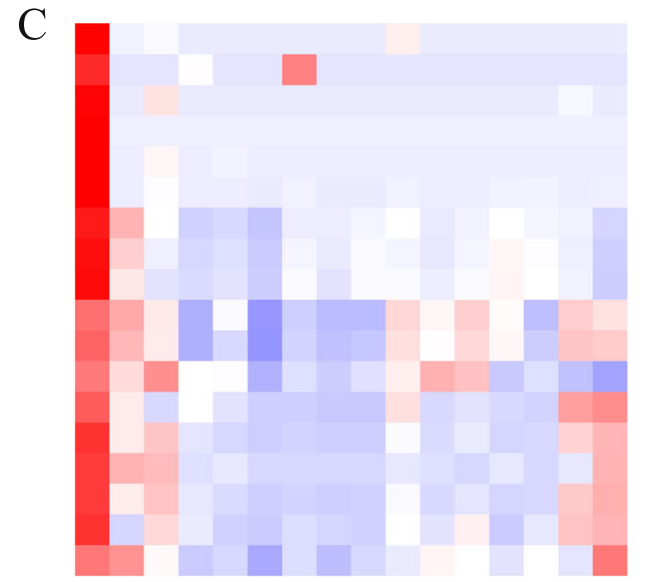

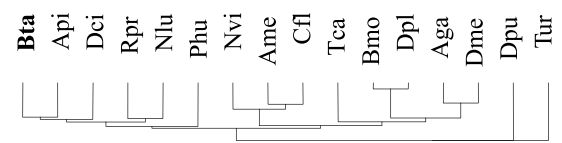

IPR018631 AAA-ATPase-like_dom. IPR018272 PRANC_domain

IPR011024 G_crystallin-rel

IPR000028 Chloroperoxidase IPR008081 Cytoplasmic FMR1-int IPR008914 PtdEtn-bd_prot_PEBP IPR015902 Glyco hydro 13 IPR006047 Glyco_hydro_13_cat_dom IPR006589 Glyco hydro 13 sub cat dom IPR017853 Glycoside hydrolase_SF IPR013781 Glyco_hydro_catalytic_dom IPR005828 MFS sugar transport like IPR000169 Pept_cys_AS IPR013128 Peptidase C1A IPR015643 Peptidase_C1A_cathepsin-B IPR000668 Peptidase_C1A_C IPR013201 Prot inhib I29 IPR002213 UDP glucos trans

B

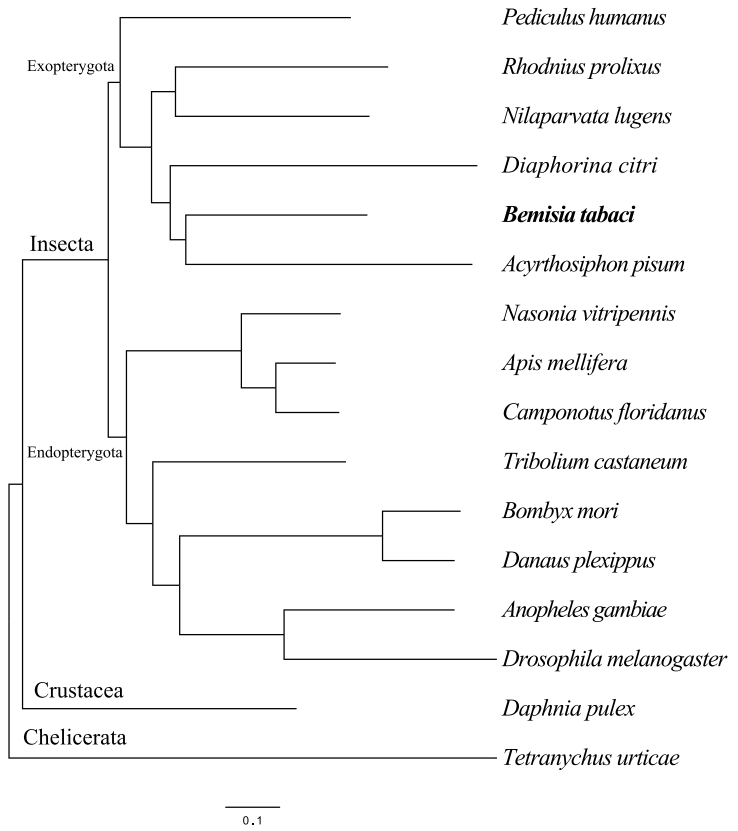

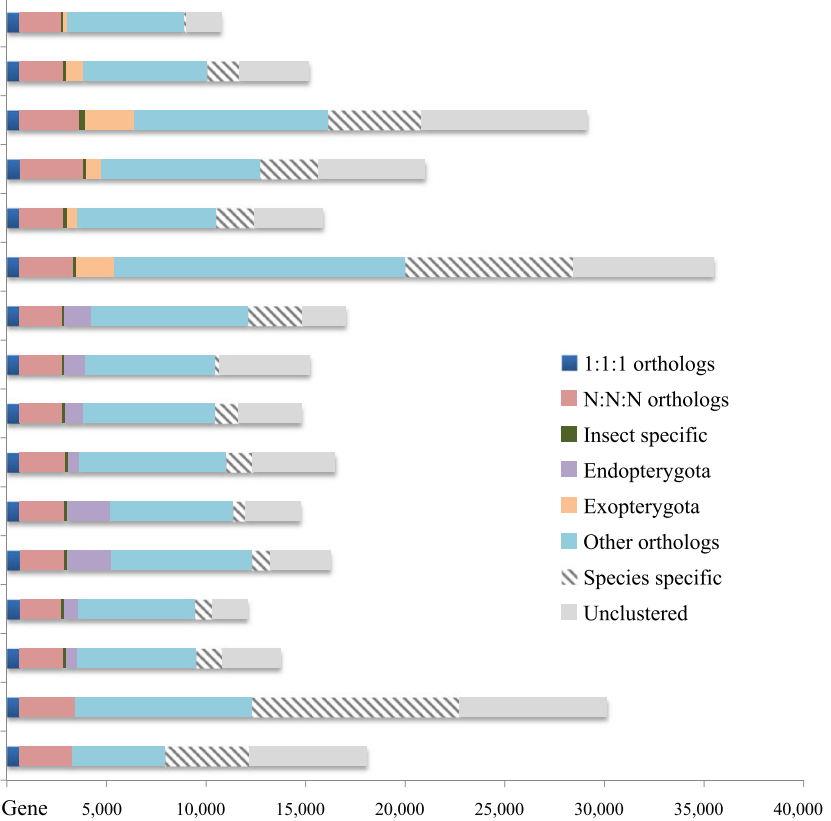

Fig. 1 Whitefly phylogenomics and gene family expansions. a Adult whiteflies Bemisia tabaci. $q$ female, ô male. b Phylogenetic relationship and gene orthology of B. tabaci and other arthropods. 1:1:1 indicates single-copy genes in all species; N:N:N indicates multi-copy genes in all species; Insect specific refers to genes present only in the 14 insect species; Endopterygota refers to genes present only in at least two endopterygotan insects; Exopterygota refers to genes present only in at least two exopterygotan insects. c Significantly expanded domains in B. tabaci. Bta B. tabaci, Api Acyrthosiphon pisum, Dci Diaphorina citri, Rpr Rhodnius prolixus, Nlu Nilaparvata lugens, Phu Pediculus humanus, Nvi Nasonia vitripennis, Ame Apis mellifera, Cfl Camponotus floridanus, Tca Tribolium castaneum, Bmo Bombyx mori, Dpl Danaus plexippus, Aga Anopheles gambiae, Dme Drosophila melanogaster, Dpu Daphnia pulex, Tur Tetranychus urticae

estimated size of $\sim 690 \mathrm{Mb}$ [28]. De novo assembly using Illumina and PacBio sequences resulted in a final draft genome of $615.0 \mathrm{Mb}$ with an N50 scaffold size of $3.23 \mathrm{Mb}$, which spanned $89.1 \%$ of the B. tabaci genome (Table 1 ). Quality evaluation using software involving Benchmarking Universal Single-Copy Orthologs (BUSCO) [29] revealed that $96.8 \%$ of the core eukaryotic genes were captured by the $B$. tabaci genome assembly and $94.4 \%$ were complete. In addition, the high mapping rates of the published whitefly mRNA sequences as well as our paired-end RNA-Seq reads further supported the high quality of the B. tabaci genome assembly (Additional files 3 and 4).

A total of $276.9 \mathrm{Mb}(45 \%)$ of repeat sequences were identified in the B. tabaci genome, which is slightly 
Table 1 Summary of the Bemisia tabaci MEAM1 genome assembly

\begin{tabular}{lll}
\hline & Scaffold $^{\mathrm{a}}$ & Contig $^{\mathrm{a}}$ \\
\hline Total number & 19,762 & 52,037 \\
Total sequences bp & $615,077,135$ & \\
Maximum length & $11,178,615$ & 269,706 \\
N50 length & $3,232,964$ & 29,920 \\
L50 number & 56 & 5750 \\
N90 length & 381,346 & 6117 \\
L90 number & 229 & 22,027 \\
Gap length & $14,380,491$ & 0 \\
\hline
\end{tabular}

anly contigs and scaffolds > =500 bp were included in the genome assembly

higher than that of the related hemipteran Acyrthosiphon pisum genome (38\%) [30]. Among these repeats, $\sim 170.5 \mathrm{Mb}(28 \%)$ were annotated as miniature invertedrepeat transposable elements (MITEs), while $79.7 \mathrm{Mb}$ (13\%) could not be classified into any known families (Additional file 5). A total of 15,664 protein-coding genes were predicted in the $B$. tabaci genome, among which $13,562(87 \%)$ were supported by our RNA-Seq data, 7321 (47\%) by homologous proteins, and 6473 (41\%) by both. Of these, $81 \%$ were functionally annotated (Additional file 6). Despite the different sizes of the assembled B. tabaci $(615.0 \mathrm{Mb})$ and D. melanogaster $(142.6 \mathrm{Mb})$ genomes, the number of protein-coding genes in the two species was similar (15,664 versus 13,920). The mean coding sequence length of the genomes was also similar, while the mean intron and untranslated region (UTR) lengths in $B$. tabaci were considerably larger than those in $D$. melanogaster (Additional file 7).

\section{Genome-based phylogeny and genome comparisons}

We compared B. tabaci protein-coding genes with those of five exopterygotan insects, eight endopterygotan insects, and two non-insect arthropod species (Additional file 8) to identify orthologous groups. The phylogeny of these 16 species, based on 642 single-copy orthologous genes, shows that $B$. tabaci is a sister taxon to A. pisum (pea aphid), forming a lineage together with three other hemipteran insects: Nilaparvata lugens (brown planthopper), Rhodnius prolixus (Triatomid bug), and Diaphorina citri (Asian citrus psyllid) (Fig. 1b). Interestingly, no syntenic blocks were identified between any of these hemipteran genomes. This is different from the Lepidoptera Heliconius melpomene (butterfly), Bombyx mori (silkworm), and Plutella xylostella (diamondback moth), whose genomes share high synteny [31]. Our analysis suggests that genomes of the five hemipteran insects, $B$. tabaci, A. pisum, N. lugens, $R$. prolixus, and D. citri, are highly divergent, consistent with previous reports suggesting that B. tabaci and A. pisum diverged about 250 million years ago [32], whereas $H$. melpomene and B. mori diverged about 103 million years ago [33].

Among the 15,664 genes in the B. tabaci genome, 10,334 (8372 gene families) had detectable homologs in the other 15 arthropods, including 2817 (2427 gene families) that were conserved in all 16 species (Fig. 1b). A total of 5330 genes (3885 gene families) including 3417 single-copy genes were found to be unique in $B$. tabaci. Furthermore, a total of 18 protein domains, which represented 10 gene families, were found to be significantly expanded in B. tabaci (Fig. 1c and Additional file 9). These expanded gene families include those that are potentially involved in virus transmission or insecticide resistance, in addition to those that were horizontally transferred (see Discussions below).

\section{Vector for plant virus transmission}

Bemisia tabaci is one of the most prevalent and agriculturally important vectors of plant viruses, capable of transmitting viruses from at least five genera [34]. We compared transcriptome profiles of whiteflies during the first three days of virus acquisition feeding on tomato plants infected with TYLCV (genus Begomovirus), which is transmitted by $B$. tabaci in a persistent circulative manner, or Tomato chlorosis virus (ToCV, genus Crinivirus), which is transmitted in a semipersistent, noncirculative manner, to the corresponding whiteflies feeding on virus-free tomato plants for the same time periods. We found that during the acquisition feeding of TYLCV- or ToCV-infected tomato plants, a large number of cathepsin genes were differentially expressed including 20 cathepsin B, five cathepsin L-like, three cathepsin F, and one cathepsin F-like genes (Fig. 2a and Additional file 10). Cathepsins are proteases involved in many biological processes, including protein degradation, apoptosis, and signaling, and their activity in the late endosome and lysosome has been widely implicated in virus transmission [35, 36]. A total of 111 cathepsin genes were detected in the B. tabaci genome (Fig. 2b), representing a significant expansion when compared to the other 15 arthropod species that were examined (Additional file 11). Specifically, a large expansion of cathepsin B genes was observed, with 50 members identified, many of which were tandem duplications. In addition, the $B$. tabaci genome contains 35 cathepsin Llike genes, while none were found in the genomes of the other 15 arthropods, indicating that these unique cathepsin L-like genes represent a novel $B$. tabaci-specific clade of cathepsins (Fig. $2 b$ and Additional file 11). The expansion of cathepsin B and L-like families in B. tabaci could be tied to the tremendous efficiency of this insect species as a vector of numerous and diverse plant viruses, possibly through its involvement in immune responses to 


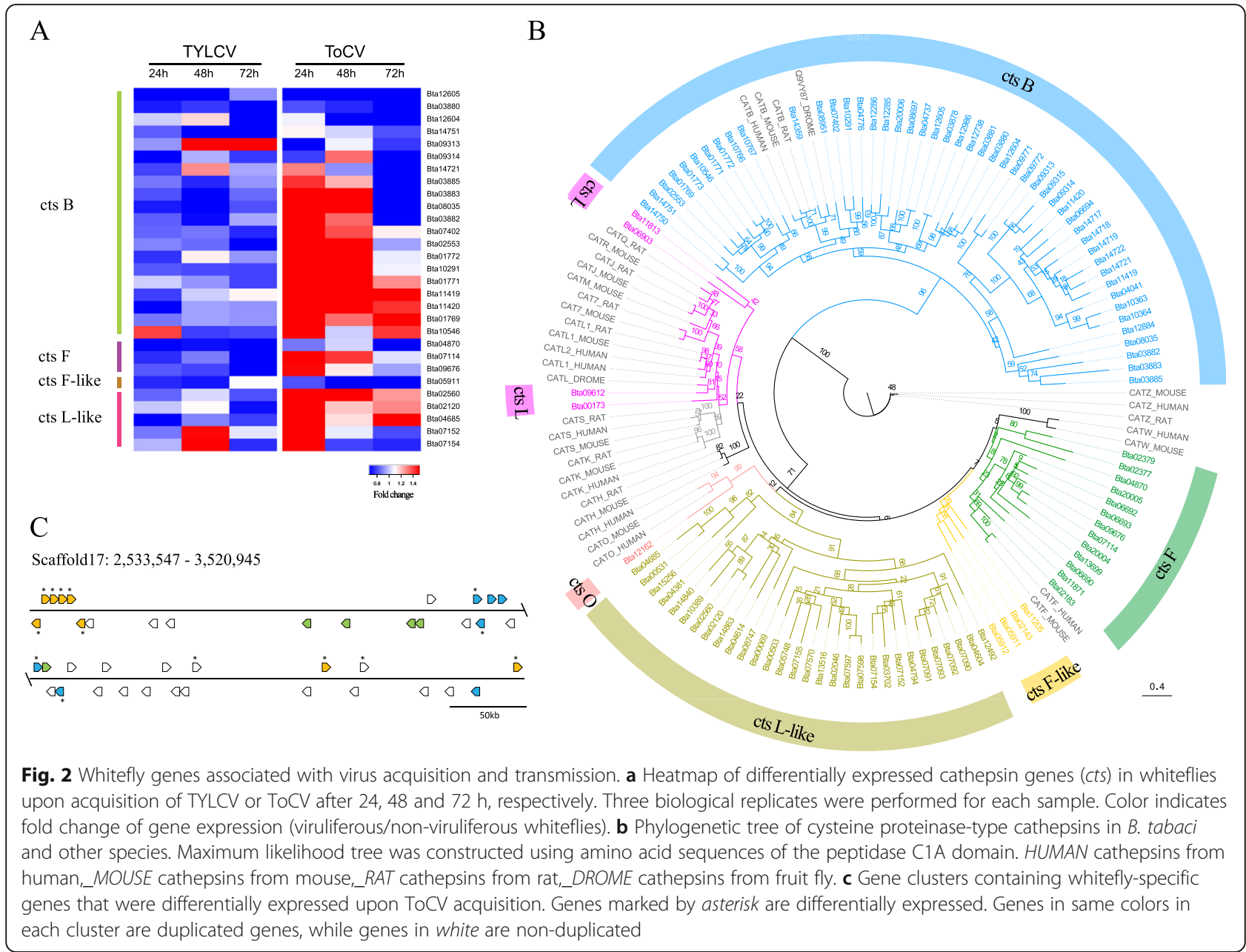

virus acquisition or other responses that govern whiteflyvirus interactions.

Interestingly, three large clusters in the B. tabaci genome were found to contain $B$. tabaci-specific unknown genes that were differentially expressed during acquisition feeding of $B$. tabaci on ToCV-infected tomato plants. Most of these genes were tandem duplications (Fig. 2c and Additional file 1: Figure S2). Our results suggest that during the evolution of $B$. tabaci, these specific genomic regions might have contributed to the elevated ability of this whitefly to transmit plant viruses, particularly non-circulative, semipersistent viruses, since these genes were not differentially expressed during feeding on tomatoes infected with the persistent, circulative virus, TYLCV. The differential expression of these unique clusters in specific association with virus acquisition feeding on ToCV-infected tomato indicates a response by the whitefly to either ToCV itself or to host factors uniquely expressed in the tomato plant during infection by ToCV. Although no function has been attributed to these genes, their expression during acquisition of $\mathrm{ToCV}$ from infected tomato plants suggests they may represent genes that are co-evolved in the whitefly vector that facilitate uptake, retention, or transmission of $\mathrm{ToCV}$ and perhaps other semipersistent viruses.

\section{Detoxification and insecticide resistance}

Bemisia tabaci is highly polyphagous, being able to feed on more than 1000 different plant species, and is notable for its rapid development of resistance to numerous insecticides. Thus, B. tabaci likely have developed the capacity to overcome a wide variety of plant defense compounds and insecticides. Several enzyme families implicated in detoxification were identified in the $B$. tabaci genome, including cytochrome P450s (CYPs), UDPglucuronosyltransferases (UGTs), glutathione S-transferases (GSTs), $A B C$ transporters (ABCs), and carboxylesterases (CCEs) (Additional file 12). The B. tabaci genome contains 130 CYPs, representing a significant expansion relative to most insects with genomes sequenced. Notable expansions include a novel family (CYP3133) with 20 members, the CYP4CS subfamily with 14 genes, and the CYP402C subfamily with 12 members (Additional file 1: Figure S3 and 
Additional file 13). The B. tabaci genome encodes 81 UGTs, similar to Tetranychus urticae (81) and $A$. pisum (72), but substantially more than the amount found in other insects (4 to 38). Additionally, 22 GST (Additional file 1: Figure S4), 50 ABC (Additional file 1: Figure S5), and 51 CCE genes were detected in the $B$. tabaci genome. Expansion of some of these detoxification gene families in $B$. tabaci likely provides a basis for its well-known insecticide resistance and its ability to occupy a broad range of host plants with a diversity of defenses.

Currently, the MEAM1 and MED cryptic species of $B$. tabaci are the most widely prevalent throughout the world and have greatly expanded their ranges over the past two decades, with MED having developed broader insecticide resistance than MEAM1 [37]. We compared global transcriptome profiles of a susceptible MED population (PyriR), as well as a resistant MED population (9-2013), with and without treatment with the insecticide Mospilan (acetamiprid). As expected, all of the aforementioned detoxification families contained genes that were responsive to Mospilan treatment in both susceptible and resistant populations, supporting their roles in whitefly insecticide resistance (Fig. 3a and Additional file 14). Interestingly, numerous genes from the highly expanded cathepsin family were differentially expressed upon Mospilan treatment, with 26 and 12 in susceptible and resistant populations, respectively. Cathepsins have been associated with the polyphagous habit of the whitefly [38]. This and the novel role of cathepsins in insecticide resistance revealed here suggest that cathepsins might have contributed to the global invasiveness of the whitefly.

In addition, the phosphatidylethanolamine-binding protein (PEBP) gene family, which has not been previously associated with detoxification or insecticide resistance in insects, showed striking responses to Mospilan treatment. A total of 134 and 16 PEBP genes were responsive to Mospilan treatment in the MED resistant and susceptible populations, respectively, all of which were down-regulated (Fig. 3a and Additional file 14). PEBPs are a highly conserved group of proteins that have been identified in a wide variety of organisms [39] and associated with various biological processes,

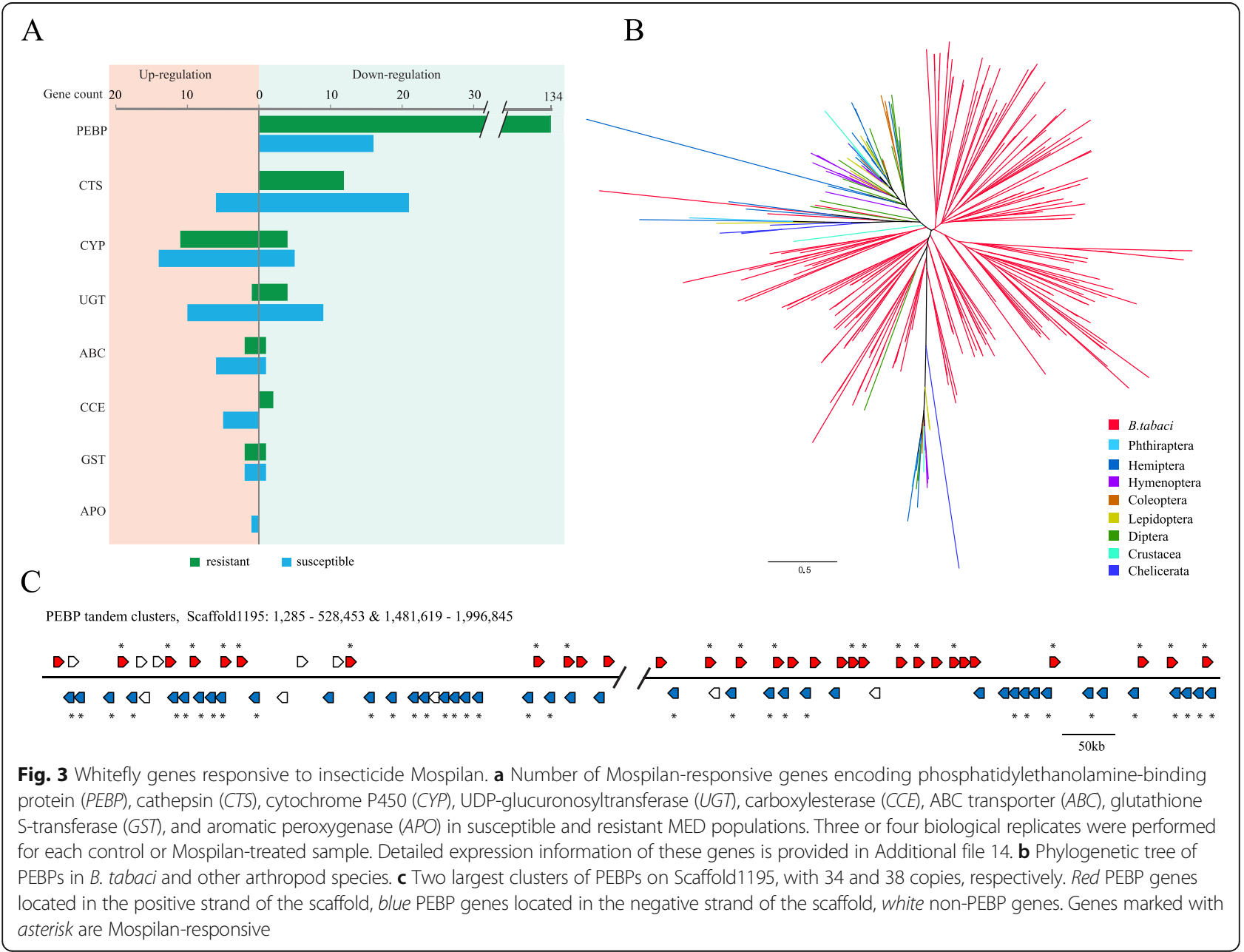


including neuronal development [40], serine protease inhibition [39], and regulation of mitogen-activated protein (MAP) kinase [41] and NF-kappaB [42] signaling pathways. Our analysis supports a novel and very important role for the PEBPs in insect resistance to pesticides. The B. tabaci genome contained 202 PEBPs, representing a tremendously expanded gene family and containing several new clades/subfamilies (Fig. 3b). By comparison, the genomes of the other 15 arthropods had a maximum of 16 PEBPs. Among the B. tabaci PEBPs, 127 were located in five large tandem clusters, the majority of which were responsive to insecticide treatment (Fig. 3c and Additional file 1: Figure S6). Our data suggest a strong role for PEBPs in $B$. tabaci insecticide resistance; the large expansion of this family may have contributed to its rapidly evolved insecticide resistance.

\section{Endosymbiont genomes}

Whiteflies harbor endosymbiotic bacteria, comprising a primary symbiont Portiera aleyrodidarum and one or more additional bacteria, generically known as secondary symbionts [43]. Diagnostic PCR assays using the primers described in Pan et al. [43] indicated that the colony of MEAM1 used for genome sequencing bore the primary endosymbiont, Portiera, and two secondary endosymbionts, Hamiltonella and Rickettsia. The genomes of the three endosymbionts were assembled de novo, with each assembled into a single contig. The assembled genome of Portiera was complete with a size of $352 \mathrm{~kb}$, while those of Hamiltonella and Rickettsia were nearly complete, with sizes of $1.74 \mathrm{Mb}$ and $1.38 \mathrm{Mb}$, respectively (Additional file 1: Figure S7 and Additional file 15). In Portiera, 273 genes were predicted, suggesting that it has a highly reduced genome largely comprising genes essential for basic cellular processes and whitefly nutrition. By contrast, 1627 and 1347 genes were predicted in Hamiltonella and Rickettsia, respectively. Hamiltonella possesses 94 (5.8\%) phage genes and numerous genes involved in the type II/III secretion systems. Approximately $22 \%$ of the Rickettsia genes are homologous to transposable elements, suggesting that the genome is highly dynamic. Comparative analysis of the B. tabaci genome with the Portiera and Hamiltonella genomes identified genes coding for complementary reactions in multiple metabolic pathways, including essential amino acid biosynthesis (Additional file 1: Figure S8 and Additional file 16), as reported previously [24, 44]. Analysis of the Rickettsia genome also shows the absence of genes for non-essential amino acid biosynthesis (Additional file 1: Figure S8 and Additional file 16). Neither $B$. tabaci nor any of the endosymbiont bacteria appear to encode known enzymes that catalyze the conversion of histidinol to histidine, suggesting that one or more of these organisms might contain a non-canonical enzyme for the final step of histidine biosynthesis. The biosynthetic pathway leading from homoserine to methionine is incomplete in B. tabaci and its endosymbionts. However, B. tabaci does encode homocysteine methyltransferase, an enzyme that produces methionine from S-methylmethionine, one of the most abundant sulfur transport molecules in plants [45]. The homocysteine necessary for this reaction can be produced as a by-product of the $\mathrm{S}$-adenosylmethionine cycle, which is present in B. tabaci and its endosymbionts. Almost all genes of the branched-chain amino acid biosynthesis pathways are present in Portiera. It is notable that branched chain amino acid aminotransferase, the only gene missing in Portiera, is present in both B. tabaci and Rickettsia, indicating that these two organisms can independently produce leucine, isoleucine, and valine from the respective oxo-acids.

\section{Genes acquired horizontally from bacteria and fungi}

The recent rapid accumulation of genomic data has facilitated the identification of increasing numbers of horizontally acquired exogenous DNA sequences in the genomes of animals, including insects [46]. We identified 142 horizontal gene transfers (HGTs) in the $B$. tabaci genome, with 64 of bacterial origin (Additional file 17) and 78 of fungal origin (Additional file 18). Recent reports on HGTs in the tardigrade genomes $[47,48]$ have demonstrated the importance of carefully examining eukaryotic genome assemblies to distinguish contaminants from authentic HGTs. In this study, we provide multiple lines of evidence to support the identified HGTs, including the alignments of paired-end and mate pair DNA reads and polyA-enriched strandspecific RNA-Seq reads (see Methods for details; Additional file 1: Figure S9; Additional files 17 and 18). In addition, our RNA-Seq data indicated that most of the HGTs were moderately or highly expressed, and 10 HGTs of bacterial origin were previously confirmed by qPCR [24]. Together, our data strongly support the high confidence of the identified HGTs in the B. tabaci genome.

The majority of the B. tabaci HGTs (93) had predicted enzymatic functions. HGTs of bacterial origin mainly contributed to amino acid synthesis, vitamin synthesis, and lipid metabolism, while those of fungal origin mainly contributed to carbohydrate processes, pro-oxidant functions, and lipid metabolism. Two cases of co-transfer of two genes were identified: bioA-bioD phylogenetically allied with the bacterium Cardinium and panB-panC allied with the bacterium Pseudomonas, which encode enzymes in the biosynthesis pathways of biotin (vitamin B7) and pantothenate (vitamin B5), respectively. The bioA and bioD genes are adjacent to one 
another in the Cardinium genome; however, in the $B$. tabaci genome they are arranged as two sets of adjacent genes, with the bioA truncated in one pair (Bta00841), and bioD truncated in the second pair (Bta01938) (Additional file 1: Figure S10), suggesting that the genes were duplicated and pseudogenized due to functional redundancy. In the other case, $p a n B$ and $p a n C$ are two adjacent genes in Pseudomonas, but become a single gene in the $B$. tabaci genome and have acquired introns (Fig. 4a and Additional file 1: Figure S9). It has been reported that genes of bacterial origin can acquire introns after their transfer into eukaryotic genomes $[49,50]$, and a large portion of B. tabaci HGTs of bacterial origin also contain introns (Additional file 17). However, as far as we know, no reports have described that two adjacent bacterial genes might have been fused into one gene and acquired introns after horizontal transfer. This arrangement of panB and panC in B. tabaci likely promotes coordinated enzymatic functions. The PanB and PanC domains of the fused protein are predicted to mediate the proximal and final reactions in pantothenate synthesis. Neither B. tabaci nor its primary endosymbiont Portiera apparently possesses the canonical gene, panE, mediating the intermediate step. However, Portiera does have $i l v C$, which has been shown to mediate the panE reaction in another symbiotic bacterium (Buchnera in aphids) [51], suggesting that B. tabaci-Portiera association may be capable of pantothenate synthesis by a shared metabolic pathway between the horizontally acquired gene in the insect genome and the symbiont gene (Fig. 4b).

The B. tabaci genome contains a gene of fungal origin annotated as squalene synthase (Additional file 18), which mediates the first committed reaction in sterol synthesis, and seven genes of bacterial origin coding for squalene-hopene cyclases (Fig. 4c and Additional file 17), which are predicted to synthesize hopanoids, the bacterial analogs of sterols. In animals, including insects, sterols function to maintain the structural integrity of membranes and also act as hormones (e.g., the ecdysteroid molting hormones of insects) [52]. Although most animals can synthesize sterols, insects and other arthropods lack this metabolic capability and are generally dependent on a dietary supply of sterols [53]. The potential capacity of $B$. tabaci to synthesize sterols/hopanoids, which would negate their dietary requirement, may be of selective advantage given that phloem sap has low sterol content [54], and may contribute to the exceptionally wide host range of this whitefly species.

We detected 20 aromatic peroxygenase (APO) genes of fungal origin in the $B$. tabaci genome, but none were present in any other insect genomes. APOs function in detoxification by selectively hydroxylating the aromatic ring of toxic compounds such as naphthalene [55]. In

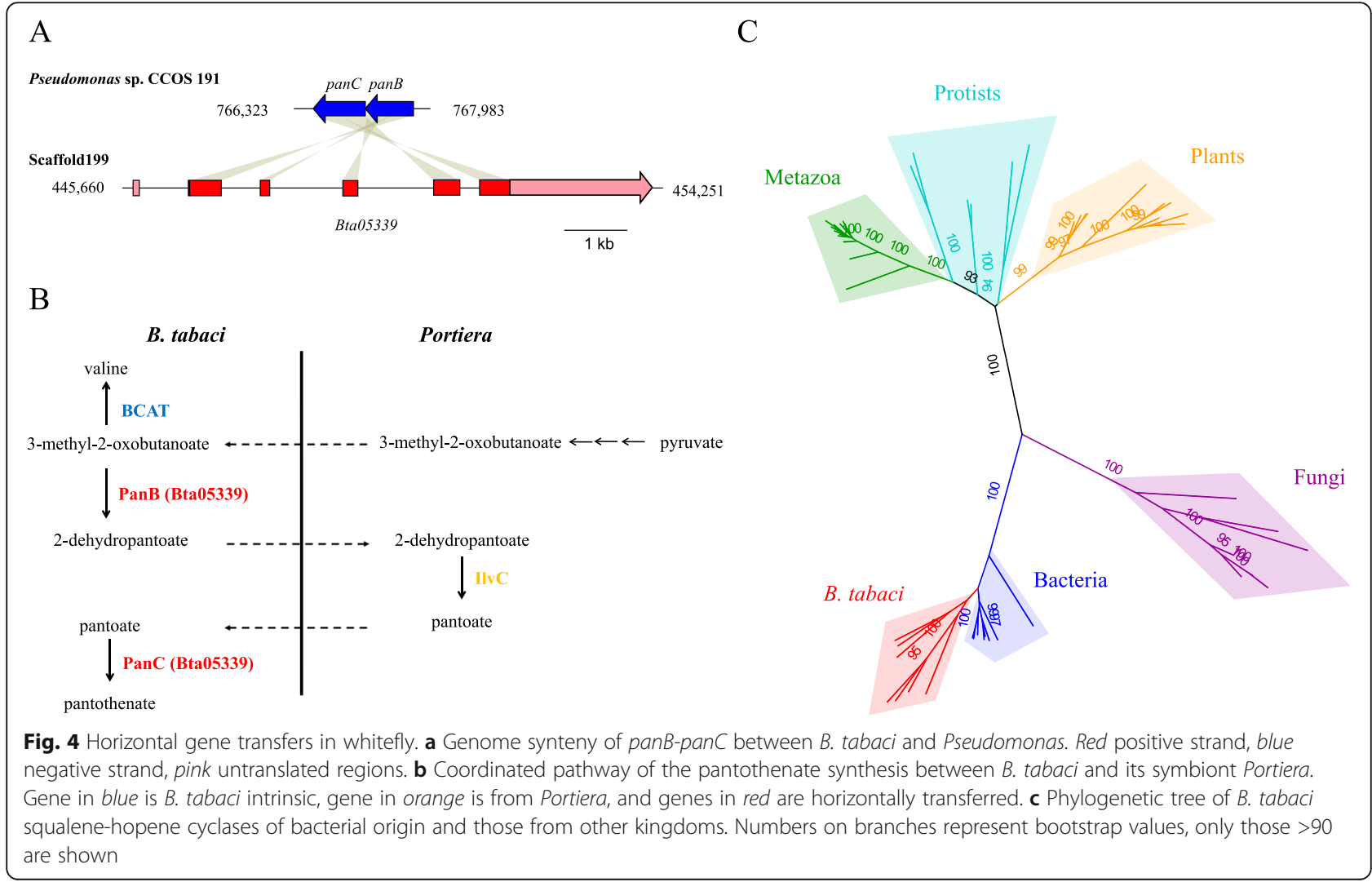


fungi, these enzymes have been implicated in the degradation of complex plant biomolecules [56]. One of the APOs was differentially expressed upon treatment with the insecticide Mospilan (Fig. 3a). We hypothesize that expression of the horizontally transferred APOs could contribute to the insecticide resistance of whiteflies as well as their high capacity for xenobiotic detoxification.

\section{Conclusions}

The whitefly $B$. tabaci represents one of the most agronomically significant pests. Our analysis of the B. tabaci genome also included chemosensory genes, immunityrelated genes, and genes in the RNA interference (RNAi) pathway (Additional file 1: Supplementary text, Figures S11 and S12; Additional files 19 and 20). Analyses of the B. tabaci genome reveal numerous genetic novelties that likely have shaped whiteflies as a highly invasive pest of agricultural crops and as one of the most prevalent and efficient transmitters of plant viruses. These include (1) several $B$. tabaci-specific gene clusters that are tandemly duplicated and uniquely responsive to feeding on virusinfected plants; (2) largely expanded gene families including cathepsins, CYPs, UGTs, and PEBPs that have potential roles in virus transmission, polyphagy, detoxification, and/or insecticide resistance; and (3) numerous genes horizontally transferred from bacteria and fungi, including those involved in essential amino acid and hopanoid/sterol synthesis, in addition to APOs with putative roles in detoxification. The B. tabaci genome reported here provides an important advance for understanding whitefly biology, with implications for insect pest management and associated virus control. Furthermore, the B. tabaci genome represents the first genome sequence in the Aleyrodidae family and is highly divergent from other sequenced hemipteran genomes, providing a valuable resource for future comparative and evolutionary genomic studies.

\section{Methods}

Genome sequencing, assembly, and annotation

Genomic DNA was isolated from approximately 6500 haploid male individuals from a B. tabaci MEAM1 colony established from a single female collected at the USDA-ARS in Charleston, SC, USA in April 2013, as described in Chen et al. [28]. The colony was validated as MEAM1 using primers specific to the mitochondrial cytochrome oxidase I (MtCOI) gene. Primer sequences used were: Btab-B (MEAM1) F:5'- CTAGGGTTTAT TGTTTGAGGTCATCATATATTC-3', R:5' - AATATCGA CGAGGCATTCCCCCT-3'; Btab-Q (MED) F:5'- CTT GGTAACTCTTCTGTAGATGTGTGTT-3', R:5'- CCTT CCCGCAGAAGAAATTTTGTTC-3'; Btab-NW (New World) F:5' - TACTGTTGRAATAGATGTTGACACTC GGG-3', R:5'- GGAAAAAATGTCAGRTTTACTCCCW CAAATATT-3', Btab-Uni (universal Bemisia tabaci) F:5'-
GAGGCTGRAAAATTARAAGTATTTGG-3', R:5'- CTT AAATTTACTGCACTTTCTGCCAYATTAG-3' which amplified $478 \mathrm{bp}, 303 \mathrm{bp}, 405 \mathrm{bp}$, and $745 \mathrm{bp}$ of the MtCOI gene, respectively [27]. PCR amplifications were performed in $20 \mathrm{ul}$ reactions using GoTaq Green Master Mix (Promega, USA), $0.25 \mathrm{uM}$ of each forward and reverse primer, and $150 \mathrm{ng}$ DNA with initial denaturation at $95{ }^{\circ} \mathrm{C}$ for $2 \mathrm{~m}, 35$ cycles of denaturation at $95^{\circ} \mathrm{C}$ for $30 \mathrm{~s}$, annealing at $46{ }^{\circ} \mathrm{C}$ (Btab-Uni) or $64{ }^{\circ} \mathrm{C}$ (Btab-B, -Q, $-\mathrm{NW}$ ) for $1 \mathrm{~m}$, extension at $72{ }^{\circ} \mathrm{C}$ for $1 \mathrm{~m}$, and a final extension at $72{ }^{\circ} \mathrm{C}$ for $5 \mathrm{~m}$. PCR products were visualized on a $1 \%$ agarose gel.

Three Illumina paired-end libraries, with insert sizes of approximately $300 \mathrm{bp}, 500 \mathrm{bp}$, and $1 \mathrm{~kb}$, and three Illumina mate pair libraries, with insert sizes of $3-5 \mathrm{~kb}$, 8-10 kb, and $15-20 \mathrm{~kb}$, were constructed using the Genomic DNA Sample Prep kit and the Nextera Mate Pair Sample Preparation kit, respectively, following the manufacturer's instructions (Illumina, San Diego, CA, USA). These libraries were sequenced on the Illumina HiSeq 2500 system. In addition, one PacBio library was prepared and sequenced on a total of 27 SMRT cells of the PacBio RSII Sequencing System using the P5C3 chemistry (Pacific Biosciences, Menlo Park, CA, USA).

The Illumina reads were first processed to collapse duplicate read pairs into unique read pairs. Duplicate read pairs were defined as those having identical bases in the first $100 \mathrm{bp}$ of both left and right reads. Illumina adapter and low-quality bases were trimmed from the reads using Trimmomatic [57]. Reads shorter than 40 bp were discarded. Errors in the Illumina sequencing reads were further corrected using Quake [58]. Sequencing errors in PacBio reads were corrected with PBCR [59] using the Illumina paired-end reads. For de novo assembly, the high-quality cleaned reads from the Illumina paired-end and mate pair libraries were first assembled using Platanus [60] with parameters of "-s 5 -c 5 -u 0.2". Gaps within each scaffold in the resulting genome assembly were filled with Illumina paired-end reads using GapCloser [61]. The error-corrected PacBio long reads were subsequently used to further fill gaps in the scaffolds and to connect scaffolds using PBJelly [62]. The assembled scaffolds were polished with iCORN2 [63] using paired-end Illumina reads to correct base errors. The assembled scaffolds were then aligned against the National Center for Biotechnology Information (NCBI) nonredundant nucleotide (nt) database using BLASTN with an e-value cut-off of 1e-5. Scaffolds with more than $90 \%$ of their length similar to bacterial sequences were considered contaminants and removed. To remove further redundant sequences in the assembly, scaffolds were blasted against themselves, and those contained within other scaffolds with sequence identity $>99 \%$ and coverage $>99 \%$ were removed. 


\section{Transcriptome sequencing and analysis}

Eggs, nymphs, and pupae were collected from leaves of collard plants (Brassica oleracea L.) on which the isogenic MEAM1 colony was reared. Tissues were surface sterilized by submersion in a petri dish containing $70 \%$ ethanol. The eggs were gently separated from nymphs and pupae using a small paintbrush. Isolated nymph and pupa samples were rinsed with sterile water. Approximately 1500 adult whiteflies reared on broccoli $(B$. oleracea L. var. botrytis) at the USDA-ARS in Charleston, SC were transferred to either TYLCV-infected or uninfected tomato (Solanum lycopersicum cv. Moneymaker) cuttings and allowed to feed for 24,48 , or $72 \mathrm{~h}$, respectively. For each treatment and time point, two compound leaves were collected from TYLCV-infected or uninfected plants and transferred to a flask filled with water, which was then sealed with Parafilm and placed in an insect-proof cage. Whiteflies were added to each cage and allowed to feed for 24,48 , or $72 \mathrm{~h}$ under controlled conditions at $28 \pm 1{ }^{\circ} \mathrm{C}$, a 14:10 (L:D) h photoperiod, and $\sim 60 \%$ humidity. A total of 200-500 living whiteflies were collected at the end of each time point and stored at $80{ }^{\circ} \mathrm{C}$ until processing. Three biological replicates were performed for each sample. A similar experiment under the same environmental conditions was performed using adults from a MEAM1 colony maintained at the USDAARS in Salinas, California (CA), but these white flies were fed on ToCV-infected or uninfected tomato (cv. Moneymaker) plants.

For insecticide treatment experiments, adults of two MED populations, PyriR, which is susceptible to the insecticide Mospilan (acetamiprid), and 9-2103, which is resistant, were fed on cotton seedlings (Gossypium hirsutum L. cv. Acala) treated with the insecticide Mospilan at an $\mathrm{LC}_{30}$ dose (lethal concentration required to kill $30 \%$ of the population; $2 \mathrm{ppm}$ for PyriR and $100 \mathrm{ppm}$ for 9-2013) with the dipping method, as previously described [64]. Whiteflies fed on untreated cotton seedlings were used as controls. The experiments were conducted under standard rearing room conditions of $25{ }^{\circ} \mathrm{C}, 50 \%$ relative humidity, and a light regime of $10 \mathrm{~h}$ light and $14 \mathrm{~h}$ dark. Three to four biological replicates, each containing a pool of 200-500 adult whiteflies, were collected from each treatment. The insects were kept at $-80{ }^{\circ} \mathrm{C}$ until use.

Total RNA was purified using the Ambion TRIzol Reagent (Thermo Fisher, USA) according to the manufacturer's protocol. Strand-specific RNA-Seq libraries were constructed following the protocol described in Zhong et al. [65] and sequenced on the Illumina HiSeq 2500 system. Raw RNA-Seq reads were first processed to remove adapter and low-quality sequences using Trimmomatic [57]. Reads shorter than 40 bp after trimming were discarded. The resulting reads were then aligned to the ribosomal RNA database [66] and the three bacterial symbiont genomes using Bowtie [67], allowing up to three mismatches. The aligned reads were not used for further analysis. To assist gene prediction, the high-quality cleaned RNA-Seq reads were aligned to the assembled B. tabaci genome using TopHat [68], and the aligned reads were assembled into transcripts using Cufflinks [69]. For gene expression analysis, the RNASeq reads were aligned to the assembled $B$. tabaci genome using HISAT [70]. Raw counts for each B. tabaci predicted gene were derived from the read alignments and normalized to fragments per kilobase of exon model per million mapped fragments (FPKM). Differential expression analyses were performed using edgeR [71]. The resulting raw $P$ values were adjusted for multiple testing using the false discovery rate (FDR) [72]. For each comparison, genes with FDR $<0.05$ and fold change no less than 1.5 were considered as differentially expressed genes.

\section{Annotation of repeat sequences}

Repeat elements in the B. tabaci genome were first identified de novo using RepeatModeler (http://www.repeatmasker.org/RepeatModeler.html), which integrates the output of RECON [73] and RepeatScout [74] to build, refine, and classify consensus models of putative interspersed repeats. The resulting repeat sequences were aligned to the NCBI non-redundant protein (nr) database, and those that were highly homologous to known proteins were removed. To identify repeat sequences in the $B$. tabaci genome, a library consisting of the de novo repeat elements identified by RepeatModeler and the Repbase library (http://www.girinst.org/repbase/index.html) were used to screen the assembled B. tabaci genome using RepeatMasker and RepeatRunner, which are integrated into the MAKER annotation pipeline [75]. Miniature invertedrepeat transposable elements (MITEs) were identified using MITE-Hunter [76].

\section{Protein-coding gene prediction and annotation}

Protein-coding genes in the $B$. tabaci genome were predicted with MAKER [75], which integrates the results from three different approaches: ab initio, homologous protein mapping, and transcript mapping. Augustus [77] and SNAP [78] were used for ab initio gene prediction. For homologous protein mapping, protein sequences from the SwissProt database and the Drosophila melanogaster and $A$. pisum proteomes were aligned to the $B$. tabaci genome using Spaln [79] with default parameters. For transcript mapping, the B. tabaci mRNA sequences collected from GenBank were aligned to the genome using Spaln [79], and only mRNAs aligned to the genome with coverage greater than $90 \%$ and sequence identity greater than $97 \%$ were retained. In addition, the 
alignments of the reference-guided assembled transcripts from our RNA-Seq data, i.e., the GFF file generated by Cufflinks, were directly used by MAKER. From the ab initio predicted genes, MAKER generated a set of highconfidence gene models, which were supported by transcript mapping and/or homologous protein mapping. The remaining ab initio predicted genes without evidence support were compared to the InterPro domain database [80] using InterProScan [81], and those containing InterPro domains were added into the predicted gene models. Finally, predicted gene models that overlapped with repeat sequences by $70 \%$ of their lengths were removed from the final predicted gene dataset.

The B. tabaci predicted genes were annotated by comparing their protein sequences against UniProt (TrEMBL and SwissProt), fruit fly, and pea aphid proteomes, as well as the InterPro domain database. GO annotation was performed using Blast2GO [82].

\section{Comparative genomics}

Orthologous groups were constructed with OrthoMCL [83] using the proteome sequences of B. tabaci and 13 other insects, as well as two additional non-insect arthropod species (Additional file 7). Protein sequences of single-copy gene families were aligned with MUSCLE [84]. The resulting alignments were trimmed using tri$\mathrm{mAl}$ [85] to remove positions with gaps in more than $20 \%$ of the sequences, and then used to reconstruct the phylogenetic tree using the maximum likelihood method implemented in PhyML [86], the JTT model for amino acid substitutions, and the aLRT method for branch support. Syntenic analysis between the five hemipteran genomes was performed using MCScanX [87].

A genome-wide screen for gene family expansions in the $B$. tabaci genome was performed based on InterPro domains. InterPro domains from the protein sequences of all the above 16 species were identified using InterProScan [81]. A domain was counted only once if it occurred multiple times in a protein sequence. Fisher's exact test was conducted for each domain, comparing the number of domains found in $B$. tabaci to the background, defined as the average of the counts in the other 15 species. The resulting raw $P$ values were corrected for multiple testing using FDR [72]. An InterPro domain was considered to be significantly expanded in $B$. tabaci if the FDR was less than 0.05 and the count in $B$. tabaci was the largest among the 16 species in the comparison.

\section{Symbiont genome assembly and annotation}

Diagnostic PCR assays using the primers described in Pan et al. [43] indicated that the colony of MEAM1 used for genome sequencing bore the primary endosymbiont, Portiera, and two secondary endosymbionts, Hamiltonella and Rickettsia. Primers specific to Cardinium,
Wolbachia, Fritschea, and Arsenophonus were also used in the whitefly endosymbiont screen but did not test positive. Primer sequences used were: Portiera F:5'-TG CAAGTCGAGCGGCATCAT-3', R:5'-AAAGTTCCCGC CTTATGCGT-3'; Rickettsia F:5'-GCTCAGAACGAACG CTATC-3', R:5'-GAAGGAAAGCATCTCTGC-3'; Hami ltonella F:5'-TGAGTAAAGTCTGGAATCTGG-3', R:5'AGTTCAAGACCGCAACCTC-3'; Cardinium F:5'-GCG GTGTAAAATGAGCGTG-3', R:5'-ACCTMTTCTTAAC TCAAGCCT-3'; Wolbachia F:5'-TGGTCCAATAAGTG ATGAAGAAAC-3', R:5'-AAAAATTAAACGCTACTC CA-3'; Fritschea F:5'-GATGCCTTGGCATTGATAGGCGATGAAGGA-3', R:5'-TGGCTCATCATGCAAAAGGC A-3'; Arsenophonus F:5'-CGTTTGATGAATTCATAGTC AAA-3', R:5'-GGTCCTCCAGTTAGTGTTACCCAAC3', which amplified approximately $1 \mathrm{~kb}, 0.9 \mathrm{~kb}, 0.7 \mathrm{~kb}$, $0.4 \mathrm{~kb}, 0.6 \mathrm{~kb}, 0.6 \mathrm{~kb}, 0.6 \mathrm{~kb}$ of the respective gene [43]. PCR amplifications were performed in $20 \mathrm{ul}$ reactions using GoTaq Green Master Mix (Promega, Madison, WI, USA), $0.25 \mathrm{uM}$ of each forward and reverse primer, and $150 \mathrm{ng}$ DNA with initial denaturation at $95{ }^{\circ} \mathrm{C}$ for $2 \mathrm{~m}, 30$ cycles of denaturation at $95^{\circ} \mathrm{C}$ for $30 \mathrm{~s}$, annealing at $55{ }^{\circ} \mathrm{C}$ (Wolbachia), $57^{\circ} \mathrm{C}$ (Cardinium), $58^{\circ} \mathrm{C}$ (Portiera, Hamiltonella, Arsenophonus), or $60{ }^{\circ} \mathrm{C}$ (Rickettsia, Fritschea) for $1 \mathrm{~m}$, extension at $72{ }^{\circ} \mathrm{C}$ for $1 \mathrm{~m}$, and a final extension at $72{ }^{\circ} \mathrm{C}$ for $5 \mathrm{~m}$. PCR products were visualized on a $1 \%$ agarose gel.

The genomes of the three symbionts present in $B$. tabaci, i.e., Portiera, Hamiltonella, and Rickettsia, were de novo assembled using the PacBio long reads. The error-corrected PacBio reads corresponding to the three symbiont genomes were first extracted by aligning the reads to the reference sequences of related species [88-90]. The extracted PacBio reads for each symbiont were de novo assembled using Sprai (http://zombie.cb.k.u-tokyo.ac.jp/sprai/). The final assembled contigs were corrected for base errors with iCORN2 [63] using the high-quality Illumina paired-end reads. Protein-coding genes from the three assembled genomes were predicted $\mathrm{ab}$ initio using GeneMark [91] and Glimmer [92]. The final consensus gene models were then derived using MAKER [75]. The predicted genes were functionally annotated by comparing their protein sequences against the UniProt database [93].

\section{Identification of horizontal gene transfers}

The B. tabaci genome sequences were first masked for repeat regions, and then translated in six frames. Potential polypeptides (PPPs) having lengths of at least 60 amino acids were kept. Furthermore, the high-quality and cleaned RNA-Seq datasets were de novo assembled using Trinity [94]. The assembled contigs were aligned to the B. tabaci genome, and only those that could be aligned were used in the analysis. To identify HGTs of 
bacterial origin, the assembled transcript and genometranslated PPP sequences were compared against two protein databases derived from complete proteomes in UniProt [93], one consisting of eukaryotic proteins (excluding proteins from species in Arthropoda) and the other consisting of bacterial proteins. To identify HGTs of fungal origin, the assembled transcript and genometranslated PPP sequences were compared against the eukaryotic protein database (excluding proteins from species in Arthropoda and fungus) and the other database consisting of fungus proteins. The index of horizontal gene transfer, $h$, was calculated by subtracting the bit score of the best eukaryote match from that of the best bacteria/ fungus match. We defined candidate HGTs as those with $h \geq 30$ and the bit score of the best bacterial or fungus protein hit $\geq 100$ as described in Crisp et al. [46]. For each candidate HGT, we manually checked the alignments of DNA reads and RNA-Seq reads to genomic regions containing the HGT and the neighboring intrinsic insect genes, and provide the following evidence to support the HGT: (1) alignments of mate pair DNA reads to support the assembly in regions containing the HGT and the neighboring insect genes; (2) coverage of paired-end DNA reads to support a HGT if the read depth of the HGT is similar to that of neighboring insect genes; and (3) alignments of polyA-enriched strand-specific RNA-Seq reads to support the structure and expression of the HGT. We then performed phylogenetic analysis to validate the bacterial or fungal origin of the HGTs. The protein sequence of each candidate HGT was compared against the protein databases of six taxa (archaea, bacteria, fungi, plants, metazoan, and other eukaryotes). The top five hits from each taxon were extracted, and aligned with the protein sequence of the candidate gene using ClustalW2 [95]. Each alignment was trimmed to exclude regions where gaps were more than $20 \%$ of sequences. Phylogenetic trees were constructed with PhyML [86] using a JTT model with 100 bootstraps. HGTs were considered validated if the genes were monophyletic with the bacterial or fungal taxa.

\section{Additional files}

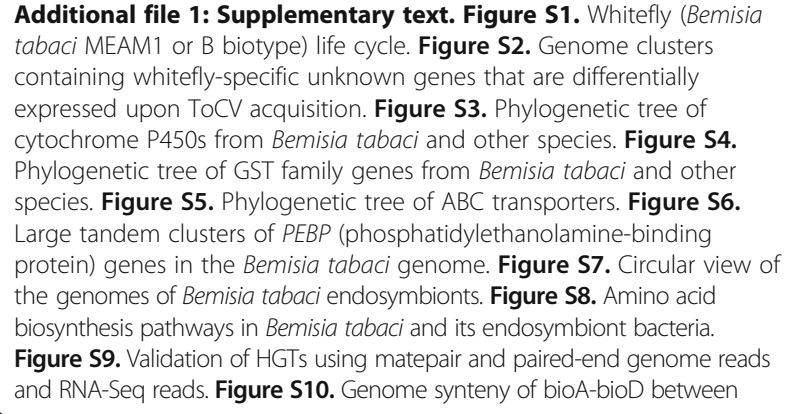

Bemisia tabaci and Cardinium. Figure S11. Number of immunity-related genes across various insect species. Figure S12. Phylogenetic analysis of Bemisia tabaci RNA-dependent RNA polymerases. (PDF 1866 kb)

Additional file 2: Summary of Bemisia tabaci genome sequencing data. (XLSX $11 \mathrm{~kb}$ )

Additional file 3: Summary of RNA-Seq dataset. (XLSX $16 \mathrm{~kb}$ ) Additional file 4: Mapping statistics of Bemisia tabaci mRNA sequences to the $B$. tabaci genome. (XLSX $11 \mathrm{~kb}$ )

Additional file 5: Repeat sequences in the Bemisia tabaci genome assembly. (XLSX 12 kb)

Additional file 6: Statistics of functional annotation of Bemisia tabaci predicted genes. (XLSX $10 \mathrm{~kb}$ )

Additional file 7: Bemisia tabaci genome annotation and comparison with fruit fly. (XLSX $11 \mathrm{~kb}$ )

Additional file 8: Source of proteomes used for comparative genomics analysis. (XLSX $12 \mathrm{~kb}$ )

Additional file 9: Domain count of expanded families in Bemisia tabaci. (XLSX $13 \mathrm{~kb}$ )

Additional file 10: Differentially expressed cathepsin and clustered unknown genes in Bemisia tabaci after acquisition of TYLCV or ToCV for 24, 48 , and 72 h, respectively. (XLSX 41 kb)

Additional file 11: Number of cathepsin genes in Bemisia tabaci as compared to other arthropods. (XLSX $10 \mathrm{~kb}$ )

Additional file 12: Number of genes potentially involved in detoxification and insecticide resistance. (XLSX $12 \mathrm{~kb}$ )

Additional file 13: Cytochrome P450 genes in Bemisia tabaci. (XLSX 50 kb) Additional file 14: Genes from detoxification and other interesting families that are differentially expressed upon insecticide treatment. (XLSX 55 kb)

Additional file 15: Endosymbiont genome assembly and annotation. (XLSX 10 kb)

Additional file 16: Amino acid biosynthesis pathway in B. tabaci and its endosymbionts. (XLSX 19 kb)

Additional file 17: Horizontally transferred genes of bacterial origin in Bemisia tabaci. (XLSX $29 \mathrm{~kb}$ )

Additional file 18: Horizontally transferred genes of fungal origin in Bemisia tabaci. (XLSX 25 kb)

Additional file 19: Immunity-related genes in Bemisia tabaci. (XLSX $11 \mathrm{~kb}$ ) Additional file 20: List of genes in the miRNA and siRNA pathways in the Bemisia tabaci genome. (XLSX $10 \mathrm{~kb}$ )

\section{Acknowledgements}

We thank Dr. Jim Giovannoni for critical reading of this manuscript, Drs. Ping Wang and Lei Gao for useful discussions, and Andrea Gilliard, April Bisner, Art Cortez, and Laura Hladky for technical assistance; we also thank the Atkinson Center for a Sustainable Future (Cornell University) for financial support. This work was supported by grants from the USDA ARS Area-wide project as a part of the i5k initiative to KSL and WMW, the USDA-ARS Office of International Research Program from a grant provided by the USAID Feed-the-Future program (58-0210-3-012) to KSL, WMW, and ZF, NSF (IOS-1110080) to ZF, and NSF (IOS-1109989 and IOS-1354309) to MC, USDA NIFA (2016-67013-24756) to GJ and AED, a Swedish Research Council U-forsk grant to MCS, and Israel Science Foundation (1127/13) to MG.

\section{Availability of data and materials}

This Whole Genome Shotgun project has been deposited at DDBJ/ENA/ GenBank under the accession MAMS00000000. The version described in this paper is version MAMS01000000. Genome and transcriptome sequence reads have been deposited in the SRA as BioProjects PRJNA312470, PRJNA312467, and PRJNA347299, respectively. A whitefly genome database is available (http://www.whiteflygenomics.org). Raw supporting data are provided in the additional files.

\section{Authors' contributions}

ZF, KSL, and WMW designed the research and managed the project. DKH and AMS maintained the whitefly colony. DKH isolated male individuals and 
prepared genomic DNA for sequencing. WC performed genome assembly, annotation, comparative genomic analysis, and RNA-Seq analysis. HS helped with genome assembly. DKH, NK, A.Kliot, SK, and GL performed the RNA-Seq experiments. YX constructed RNA-Seq libraries. YZ, DKH, and NK contributed to RNA-Seq data analysis. AED, WC, JL, and ZF contributed to the analysis of horizontally transferred genes. AED, WC, DKH, A.Kruse, MCS, DRN, GJ, JKB, JL, $M C, M G, N K, P V P, T W F, W B H, X Y$, and YL contributed to annotation and analysis of specific gene families. WL and WC implemented the whitefly genome database. The authors declare no competing financial interests. All authors read and approved the final manuscript.

\section{Competing interests}

The authors declare that they have no competing interests.

\section{Author details}

${ }^{1}$ Boyce Thompson Institute, Cornell University, Ithaca, NY 14853, USA. ${ }^{2}$ US Department of Agriculture-Agricultural Research Service, US Vegetable Laboratory, Charleston, SC 29414, USA. ${ }^{3}$ US Department of

Agriculture-Agricultural Research Service, Crop Improvement and Protection Research, Salinas, CA 93905, USA. ${ }^{4}$ Department of Entomology, The Volcani Center, Bet Dagan 50250, Israel. ${ }^{5}$ EMBRAPA Rice and Beans, Santo Antônio de Goiás, GO 75375-000, Brazil. ${ }^{6}$ Department of Entomology, Cornell University, Ithaca, NY 14853, USA. ${ }^{7}$ Department of Biology, Lund University, Lund SE-223 62, Sweden. ${ }^{8}$ Department of Plant Pathology and Plant-Microbe Biology, Cornell University, Ithaca, NY 14853, USA. ${ }^{9}$ Department of Plant Sciences, The University of Arizona, Tucson, AZ 85721, USA. ${ }^{10}$ Department of Microbiology, Immunology and Biochemistry, University of Tennessee Health Science Center, Memphis, TN 38163, USA. ${ }^{11}$ US Department of Agriculture-Agricultural Research Service, US Horticultural Laboratory, Fort Pierce, FL 34945, USA. ${ }^{12}$ US Department of Agriculture-Agricultural Research Service, Robert W. Holley Center for Agriculture and Health, Ithaca, NY 14853, USA.

Received: 2 September 2016 Accepted: 28 October 2016

\section{Published online: 14 December 2016}

\section{References}

1. Martin J, Mound L. An annotated check list of the world's whiteflies (Insecta: Hemiptera: Aleyrodidae). Lista de las moscas blancas del mundo (Insecta: Hemiptera: Aleyrodidae). Zootaxa. 2007;1:1-84.

2. Abd-Rabou S, Simmons AM. Survey of reproductive host plants of Bemisia tabaci (Hemiptera: Aleyrodidae) in Egypt, including new host records. Entomol News. 2010;121:456-65.

3. Navas-Castillo J, Fiallo-Olive E, Sanchez-Campos S. Emerging virus diseases transmitted by whiteflies. Annu Rev Phytopathol. 2011;49:219-48.

4. K-b S, Adkins S, Czosnek H, Palukaitis P, Jacquot E, Hohn T, Hohn B, Saunders K, Candresse T, Ahlquist P. Top 10 plant viruses in molecular plant pathology. Mol Plant Pathol. 2011;12:938-54.

5. Lefeuvre P, Martin DP, Harkins G, Lemey P, Gray AJ, Meredith S, Lakay F, Monjane A, Lett J-M, Varsani A. The spread of tomato yellow leaf curl virus from the Middle East to the world. PLoS Pathog. 2010;6:e1001164.

6. Legg J, Jeremiah S, Obiero H, Maruthi M, Ndyetabula I, Okao-Okuja G, Bouwmeester H, Bigirimana S, Tata-Hangy W, Gashaka G. Comparing the regional epidemiology of the cassava mosaic and cassava brown streak virus pandemics in Africa. Virus Res. 2011;159:161-70.

7. Legg JP, Shirima R, Tajebe LS, Guastella D, Boniface S, Jeremiah S, Nsami E, Chikoti P, Rapisarda C. Biology and management of Bemisia whitefly vectors of cassava virus pandemics in Africa. Pest Manag Sci. 2014;70:1446-53.

8. Patil BL, Legg JP, Kanju E, Fauquet CM. Cassava brown streak disease: a threat to food security in Africa. J Gen Virol. 2015;96:956-68.

9. Legg J, Somado EA, Barker I, Beach L, Ceballos H, Cuellar W, Elkhoury W, Gerling D, Helsen J, Hershey C. A global alliance declaring war on cassava viruses in Africa. Food Security. 2014;6:231-48.

10. Gennadius P. Disease of the tobacco plantations in the Trikonia. The aleurodid of tobacco. Ellenike Georgia. 1889;5:1-3.

11. Boykin LM. Bemisia tabaci nomenclature: lessons learned. Pest Manag Sci. 2014;70:1454-9.

12. Brown JK. Phylogenetic biology of the Bemisia tabaci sibling species group. In: Stansly PA, Naranjo SE, editors. Bemisia: bionomics and management of a global pest. New York: Springer; 2010. p. 31-67.
13. Alemandri V, Vaghi Medina CG, Dumon AD, Arguello Caro EB, Mattio MF, Garcia Medina S, Lopez Lambertini PM, Truol G. Three members of the Bemisia tabaci (Hemiptera: Aleyrodidae) cryptic species complex occur sympatrically in Argentine horticultural crops. J Econ Entomol. 2015;108:405-13.

14. Boykin LM, De Barro PJ. A practical guide to identifying members of the Bemisia tabaci species complex: and other morphologically identical species. Front Ecol Evol. 2014. doi:10.3389/fevo.2014.00045.

15. Boykin LM, Armstrong KF, Kubatko L, De Barro PJ. Species delimitation and global biosecurity. Evol Bioinforma. 2012;8:1-37.

16. De Barro PJ, Liu SS, Boykin LM, Dinsdale AB. Bemisia tabaci: a statement of species status. Annu Rev Entomol. 2011;56:1-19.

17. Dinsdale A, Cook L, Riginos C, Buckley YM, De Barro P. Refined global analysis of Bemisia tabaci (Hemiptera: Sternorrhyncha: Aleyrodoidea: Aleyrodidae) mitochondrial cytochrome oxidase 1 to identify species level genetic boundaries. Ann Entomol Soc Am. 2010;103:196-208.

18. Liu SS, Colvin J, De Barro PJ. Species concepts as applied to the whitefly Bemisia tabaci systematics: how many species are there?. J Integr Agri. 2012;11:176-86.

19. Wang XW, Luan JB, Li JM, Su YL, Xia J, Liu SS. Transcriptome analysis and comparison reveal divergence between two invasive whitefly cryptic species. BMC Genomics. 2011;12:458.

20. Wang XW, Zhao QY, Luan JB, Wang YJ, Yan GH, Liu SS. Analysis of a native whitefly transcriptome and its sequence divergence with two invasive whitefly species. BMC Genomics. 2012;13:529.

21. Luan JB, Li JM, Varela N, Wang YL, Li FF, Bao YY, Zhang CX, Liu SS, Wang $\mathrm{XW}$. Global analysis of the transcriptional response of whitefly to tomato yellow leaf curl China virus reveals the relationship of coevolved adaptations. J Virol. 2011;85:3330-40.

22. Ilias A, Lagnel J, Kapantaidaki DE, Roditakis E, Tsigenopoulos CS, Vontas J, Tsagkarakou A. Transcription analysis of neonicotinoid resistance in Mediterranean (MED) populations of $B$. tabaci reveal novel cytochrome P450s, but no nAChR mutations associated with the phenotype. BMC Genomics. 2015;16:939.

23. Wang XW, Luan JB, Li JM, Bao YY, Zhang CX, Liu SS. De novo characterization of a whitefly transcriptome and analysis of its gene expression during development. BMC Genomics. 2010;11:400.

24. Luan JB, Chen W, Hasegawa DK, Simmons AM, Wintermantel WM, Ling KS, Fei Z, Liu SS, Douglas AE. Metabolic coevolution in the bacterial symbiosis of whiteflies and related plant sap-feeding insects. Genome Biol Evol. 2015;7:2635-47.

25. Ye XD, Su YL, Zhao QY, Xia WQ, Liu SS, Wang XW. Transcriptomic analyses reveal the adaptive features and biological differences of guts from two invasive whitefly species. BMC Genomics. 2014;15:370.

26. Luan JB, Shan HW, Isermann P, Huang JH, Lammerding J, Liu SS, Douglas AE. Cellular and molecular remodelling of a host cell for vertical transmission of bacterial symbionts. Proc Biol Sci. 2016; 283. doi:10.1098/rspb.2016.0580.

27. Shatters Jr RG, Powell CA, Boykin LM, Liansheng H, McKenzie CL. Improved DNA barcoding method for Bemisia tabaci and related Aleyrodidae: development of universal and Bemisia tabaci biotype-specific mitochondrial cytochrome c oxidase I polymerase chain reaction primers. J Econ Entomol. 2009;102:750-8,

28. Chen W, Hasegawa DK, Arumuganathan K, Simmons AM, Wintermantel WM Fei Z, Ling KS. Estimation of the whitefly Bemisia tabaci genome size based on k-mer and flow cytometric analyses. Insects. 2015;6:704-15.

29. Simao FA, Waterhouse RM, loannidis P, Kriventseva EV, Zdobnov EM. BUSCO: assessing genome assembly and annotation completeness with single-copy orthologs. Bioinformatics. 2015;31:3210-2.

30. IAGC. Genome sequence of the pea aphid Acyrthosiphon pisum. PLoS Biol. 2010;8:e1000313.

31. Consortium HG. Butterfly genome reveals promiscuous exchange of mimicry adaptations among species. Nature. 2012;487:94-8.

32. Misof B, Liu S, Meusemann K, Peters RS, Donath A, Mayer C, Frandsen PB, Ware J, Flouri T, Beutel RG. Phylogenomics resolves the timing and pattern of insect evolution. Science. 2014;346:763-7.

33. Pringle EG, Baxter SW, Webster CL, Papanicolaou A, Lee SF, Jiggins CD. Synteny and chromosome evolution in the Lepidoptera: evidence from mapping in Heliconius melpomene. Genetics. 2007;177:417-26.

34. Ghanim M. A review of the mechanisms and components that determine the transmission efficiency of Tomato yellow leaf curl virus (Geminiviridae; Begomovirus) by its whitefly vector. Virus Res. 2014;186:47-54. 
35. Kubo Y, Hayashi H, Matsuyama T, Sato H, Yamamoto N. Retrovirus entry by endocytosis and cathepsin proteases. Adv Virol. 2012;2012:640894.

36. Sim S, Ramirez JL, Dimopoulos G. Dengue virus infection of the Aedes aegypti salivary gland and chemosensory apparatus induces genes that modulate infection and blood-feeding behavior. PLoS Pathog. 2012;8:e1002631.

37. Horowitz AR, Ishaaya I. Dynamics of biotypes B and Q of the whitefly Bemisia tabaci and its impact on insecticide resistance. Pest Manag Sci. 2014;70:1568-72

38. Alon M, Elbaz M, Ben-Zvi MM, Feldmesser E, Vainstein A, Morin S. Insights into the transcriptomics of polyphagy: Bemisia tabaci adaptability to phenylpropanoids involves coordinated expression of defense and metabolic genes. Insect Biochem Mol Biol. 2012;42:251-63.

39. Hengst $U$, Albrecht $H$, Hess D, Monard D. The phosphatidylethanolaminebinding protein is the prototype of a novel family of serine protease inhibitors. J Biol Chem. 2001;276:535-40.

40. Vallee B, Coadou G, Labbe H, Sy D, Vovelle F, Schoentgen F. Peptides corresponding to the $\mathrm{N}$-and $\mathrm{C}$-terminal parts of PEBP are well-structured in solution: new insights into their possible interaction with partners in vivo. J Pept Res. 2003;61:47-57.

41. Corbit KC, Trakul N, Eves EM, Diaz B, Marshall M, Rosner MR. Activation of Raf-1 signaling by protein kinase $C$ through a mechanism involving Raf kinase inhibitory protein. J Biol Chem. 2003;278:13061-8.

42. Yeung KC, Rose DW, Dhillon AS, Yaros D, Gustafsson M, Chatterjee D, McFerran B, Wyche J, Kolch W, Sedivy JM. Raf kinase inhibitor protein interacts with NF-kappaB-inducing kinase and TAK1 and inhibits NF-kappaB activation. Mol Cell Biol. 2001;21:7207-17.

43. Pan H, Li X, Ge D, Wang S, Wu Q, Xie W, Jiao X, Chu D, Liu B, Xu B, et al. Factors affecting population dynamics of maternally transmitted endosymbionts in Bemisia tabaci. PLoS ONE. 2012;7:e30760.

44. Rao Q, Rollat-Farnier PA, Zhu DT, Santos-Garcia D, Silva FJ, Moya A, Latorre A, Klein CC, Vavre F, Sagot MF, et al. Genome reduction and potential metabolic complementation of the dual endosymbionts in the whitefly Bemisia tabaci. BMC Genomics. 2015;16:226.

45. Ranocha P, McNeil SD, Ziemak MJ, Li C, Tarczynski MC, Hanson AD. The S-methylmethionine cycle in angiosperms: ubiquity, antiquity and activity. Plant J. 2001;25:575-84

46. Crisp A, Boschetti C, Perry M, Tunnacliffe A, Micklem G. Expression of multiple horizontally acquired genes is a hallmark of both vertebrate and invertebrate genomes. Genome Biol. 2015;16:50.

47. Koutsovoulos G, Kumar S, Laetsch DR, Stevens L, Daub J, Conlon C, Maroon $H$, Thomas F, Aboobaker AA, Blaxter M. No evidence for extensive horizontal gene transfer in the genome of the tardigrade Hypsibius dujardini. Proc Natl Acad Sci U S A. 2016;113:5053-8.

48. Boothby TC, Tenlen JR, Smith FW, Wang JR, Patanella KA, Nishimura EO, Tintori SC, Li Q, Jones CD, Yandell M, et al. Evidence for extensive horizontal gene transfer from the draft genome of a tardigrade. Proc Natl Acad Sci U S A. 2015;112:15976-81.

49. Hotopp JCD, Clark ME, Oliveira DC, Foster JM, Fischer P, Muñoz Torres MC, Giebe JD, Kumar N, Ishmael N, et al. Widespread lateral gene transfer from intracellular bacteria to multicellular eukaryotes. Science. 2007;317:1753-6.

50. Gladyshev EA, Meselson M, Arkhipova IR. Massive horizontal gene transfer in bdelloid rotifers. Science. 2008:320:1210-3.

51. Price DR, Wilson AC. A substrate ambiguous enzyme facilitates genome reduction in an intracellular symbiont. BMC Biol. 2014;12:110.

52. Wollam J, Antebi A. Sterol regulation of metabolism, homeostasis, and development. Annu Rev Biochem. 2011;80:885-916.

53. Behmer ST, Nes WD. Insect sterol nutrition and physiology: a global overview. Adv Insect Phy. 2003;31:1-72.

54. Behmer ST, Grebenok RJ, Douglas AE. Plant sterols and host plant suitability for a phloem-feeding insect. Funct Ecol. 2011;25:484-91.

55. Kluge M, Ullrich R, Dolge C, Scheibner K, Hofrichter M. Hydroxylation of naphthalene by aromatic peroxygenase from Agrocybe aegerita proceeds via oxygen transfer from $\mathrm{H}_{2} \mathrm{O}_{2}$ and intermediary epoxidation. Appl Microbiol Biotechnol. 2009;81:1071-6.

56. Hammel KE, Cullen D. Role of fungal peroxidases in biological ligninolysis. Curr Opin Plant Biol. 2008;11:349-55.

57. Bolger AM, Lohse M, Usadel B. Trimmomatic: a flexible trimmer for Illumina sequence data. Bioinformatics. 2014;30:2114-20.

58. Kelley DR, Schatz MC, Salzberg SL. Quake: quality-aware detection and correction of sequencing errors. Genome Biol. 2010;11:R116.
59. Koren S, Schatz MC, Walenz BP, Martin J, Howard JT, Ganapathy G, Wang Z, Rasko DA, McCombie WR, Jarvis ED. Hybrid error correction and de novo assembly of single-molecule sequencing reads. Nat Biotechnol. 2012;30:693-700.

60. Kajitani R, Toshimoto K, Noguchi H, Toyoda A, Ogura Y, Okuno M, Yabana M, Harada M, Nagayasu E, Maruyama H. Efficient de novo assembly of highly heterozygous genomes from whole-genome shotgun short reads. Genome Res. 2014;24:1384-95.

61. Luo R, Liu B, Xie Y, Li Z, Huang W, Yuan J, He G, Chen Y, Pan Q, Liu Y, et al. SOAPdenovo2: an empirically improved memory-efficient short-read de novo assembler. GigaSci. 2012;1:18.

62. English AC, Richards S, Han Y, Wang M, Vee V, Qu J, Qin X, Muzny DM, Reid JG, Worley KC. Mind the gap: upgrading genomes with Pacific Biosciences RS long-read sequencing technology. PLoS One. 2012;7:e47768.

63. Otto TD, Sanders M, Berriman M, Newbold C. Iterative Correction of Reference Nucleotides (iCORN) using second generation sequencing technology. Bioinformatics. 2010;26:1704-7.

64. Kontsedalov S, Zchori-Fein E, Chiel E, Gottlieb Y, Inbar M, Ghanim M. The presence of Rickettsia is associated with increased susceptibility of Bemisia tabaci (Homoptera: Aleyrodidae) to insecticides. Pest Manag Sci. 2008;64:789-92.

65. Zhong S, Joung JG, Zheng Y, Chen YR, Liu B, Shao Y, Xiang JZ, Fei Z, Giovannoni JJ. High-throughput illumina strand-specific RNA sequencing library preparation. Cold Spring Harb Protoc. 2011;2011:940-9.

66. Quast C, Pruesse E, Yilmaz P, Gerken J, Schweer T, Yarza P, Peplies J, Glockner FO. The SILVA ribosomal RNA gene database project: improved data processing and web-based tools. Nucleic Acids Res. 2013;41:D590-6.

67. Langmead B, Trapnell C, Pop M, Salzberg SL. Ultrafast and memory-efficient alignment of short DNA sequences to the human genome. Genome Biol. 2009;10:R25.

68. Trapnell C, Pachter L, Salzberg SL. TopHat: discovering splice junctions with RNA-Seq. Bioinformatics. 2009;25:1105-11.

69. Trapnell C, Williams BA, Pertea G, Mortazavi A, Kwan G, van Baren MJ, Salzberg SL, Wold BJ, Pachter L. Transcript assembly and quantification by RNA-Seq reveals unannotated transcripts and isoform switching during cell differentiation. Nat Biotechnol. 2010;28:511-5.

70. Kim D, Langmead B, Salzberg SL. HISAT: a fast spliced aligner with low memory requirements. Nat Methods. 2015;12:357-60.

71. Robinson MD, McCarthy DJ, Smyth GK. EdgeR: a bioconductor package for differential expression analysis of digital gene expression data. Bioinformatics. 2010;26:139-40.

72. Benjamini $Y$, Hochberg Y. Controlling the false discovery rate: a practical and powerful approach to multiple testing. J R Stat Soc B. 1995;289-300

73. Bao Z, Eddy SR. Automated de novo identification of repeat sequence families in sequenced genomes. Genome Res. 2002;12:1269-76.

74. Price $\mathrm{AL}$, Jones $\mathrm{NC}$, Pevzner PA. De novo identification of repeat families in large genomes. Bioinformatics. 2005;21:i351-8.

75. Cantarel BL, Korf I, Robb SM, Parra G, Ross E, Moore B, Holt C, Sanchez Alvarado A, Yandell M. MAKER: an easy-to-use annotation pipeline designed for emerging model organism genomes. Genome Res. 2008:18:188-96.

76. Han Y, Wessler SR. MITE-Hunter: a program for discovering miniature inverted-repeat transposable elements from genomic sequences. Nucleic Acids Res. 2010;38:e199.

77. Stanke M, Waack S. Gene prediction with a hidden Markov model and a new intron submodel. Bioinformatics. 2003;19:ii215-25.

78. Korf I. Gene finding in novel genomes. BMC Bioinforma. 2004:5:59.

79. Gotoh O. Direct mapping and alignment of protein sequences onto genomic sequence. Bioinformatics. 2008:24:2438-44.

80. Mitchell A, Chang HY, Daugherty L, Fraser M, Hunter S, Lopez R, McAnulla C, McMenamin C, Nuka G, Pesseat S, et al. The InterPro protein families database: the classification resource after 15 years. Nucleic Acids Res. 2015;43:D213-21.

81. Jones P, Binns D, Chang HY, Fraser M, Li W, McAnulla C, McWilliam H, Maslen J, Mitchell A, Nuka G, et al. InterProScan 5: genome-scale protein function classification. Bioinformatics. 2014;30:1236-40.

82. Conesa A, Gotz S, Garcia-Gomez JM, Terol J, Talon M, Robles M. Blast2GO: a universal tool for annotation, visualization and analysis in functional genomics research. Bioinformatics. 2005;21:3674-6.

83. Li L, Stoeckert Jr CJ, Roos DS. OrthoMCL: identification of ortholog groups for eukaryotic genomes. Genome Res. 2003;13:2178-89.

84. Edgar RC. MUSCLE: multiple sequence alignment with high accuracy and high throughput. Nucleic Acids Res. 2004;32:1792-7.

85. Capella-Gutierrez S, Silla-Martinez JM, Gabaldon T. TrimAl: a tool for automated alignment trimming in large-scale phylogenetic analyses. Bioinformatics. 2009;25:1972-3. 
86. Guindon S, Delsuc F, Dufayard JF, Gascuel O. Estimating maximum likelihood phylogenies with PhyML. Methods Mol Biol. 2009:537:113-37.

87. Wang Y, Tang H, DeBarry JD, Tan X, Li J, Wang X. Lee T-h, Jin H, Marler B, Guo H. MCScanX: a toolkit for detection and evolutionary analysis of gene synteny and collinearity. Nucleic Acids Res. 2012;40:e49.

88. Rao Q, Wang S, Su YL, Bing XL, Liu SS, Wang XW. Draft genome sequence of "Candidatus Hamiltonella defensa," an endosymbiont of the whitefly Bemisia tabaci. J Bacteriol. 2012;194:3558.

89. Rao Q, Wang S, Zhu DT, Wang XW, Liu SS. Draft genome sequence of Rickettsia sp. strain MEAM1, isolated from the whitefly Bemisia tabaci. J Bacteriol. 2012;194:4741-2.

90. Jiang ZF, Xia F, Johnson KW, Brown CD, Bartom E, Tuteja JH, Stevens R, Grossman RL, Brumin M, White KP, et al. Comparison of the genome sequences of "Candidatus Portiera aleyrodidarum" primary endosymbionts of the whitefly Bemisia tabaci B and O biotypes. Appl Environ Microbiol. 2013;79:1757-9.

91. Besemer J, Borodovsky M. GeneMark: web software for gene finding in prokaryotes, eukaryotes and viruses. Nucleic Acids Res. 2005;33:W451-4.

92. Salzberg SL, Delcher AL, Kasif S, White O. Microbial gene identification using interpolated Markov models. Nucleic Acids Res. 1998;26:544-8.

93. UniProtConsortium. UniProt: a hub for protein information. Nucleic Acids Res. 2015:43:D204-12.

94. Grabherr MG, Haas BJ, Yassour M, Levin JZ, Thompson DA, Amit I, Adiconis $X$, Fan L, Raychowdhury R, Zeng $Q$, et al. Full-length transcriptome assembly from RNA-Seq data without a reference genome. Nat Biotechnol. 2011;29:644-52.

95. Larkin MA, Blackshields G, Brown NP, Chenna R, McGettigan PA, McWilliam $\mathrm{H}$, Valentin F, Wallace IM, Wilm A, Lopez R, et al. Clustal W and Clustal X version 2.0. Bioinformatics. 2007;23:2947-8

\section{Submit your next manuscript to BioMed Central and we will help you at every step:}

- We accept pre-submission inquiries

- Our selector tool helps you to find the most relevant journal

- We provide round the clock customer support

- Convenient online submission

- Thorough peer review

- Inclusion in PubMed and all major indexing services

- Maximum visibility for your research

Submit your manuscript at www.biomedcentral.com/submit 